\title{
Occupational Outcomes Associated with Sleep Quality and Excessive Daytime Sleepiness: Results from a National Survey
}

This article was published in the following Dove Press journal: Nature and Science of Sleep

\section{Saad Mohammed AIShareef \\ Department of Medicine, College of Medicine, Imam Mohammad Ibn Saud Islamic University (IMSIU), Riyadh 13317-4233, Saudi Arabia}

Introduction: There are few population-level studies of the interactions between sleep quality/excessive daytime sleepiness (EDS) and occupational behavior. Here, we investigated the impact of sleep quality and EDS on occupational outcomes in a population-wide survey of adults in Saudi Arabia.

Methods: A population-wide survey was administered to Saudi Arabian adults to assess sleep quality, EDS was measured using the Epworth Sleepiness Scale (ESS), and sleeprelated absenteeism, sleep-related errors at work, and falling asleep at work in the preceding three months. Associations were evaluated using univariate analyses and binary logistic regression.

Results: A total of 10,106 individuals completed all or part of the survey, of whom 8617 $(85.3 \%)$ were employed. Of these, $28.7 \%$ and $8.8 \%$ of respondents reported "fairly bad" or "very bad" sleep quality in the preceding month. In binary logistic regression models, taking sleep medications was associated with absenteeism (odds ratio (OR) 1.92, 95\% confidence intervals (CI) 1.67-2.22; $\mathrm{p}<0.001$ ) and making errors at work (OR 1.89, 95\% CI 1.62-2.20; $\mathrm{p}<0.001)$ but not falling asleep at work, and poor subjective sleep quality was associated with falling asleep at work (ORs 1.55, 95\% CI 1.38-1.74; p<0.001). Severe EDS (ESS $\geq 16$ ) was strongly associated with falling asleep at work (OR 3.39, 95\% CI 2.51-4.48; $\mathrm{p}<0.001$ ). Parameters associated with absenteeism, errors, and falling asleep at work were similar in blue- and white-collar workers.

Discussion: This first population-wide study of sleep quality and EDS in Saudi Arabia provides a comprehensive portrait of the prevalence of sleep problems and their effects on occupational outcomes. Sleep-related absenteeism, work errors, and sleeping at work are common, mandating tailored fatigue-reduction strategies in every workplace and reinvigoration of public health messages on sleep.

Keywords: Epworth Sleepiness Scale, errors at work, excessive daytime sleepiness, sleep hygiene

\section{Introduction}

Sleep is essential to human health, wellbeing, and daily functioning. High-quality sleep is important for maintaining mental and physical health, both in the short and long term. ${ }^{1}$ Since sleep quality is associated with alertness and how we respond to our environment, sleep quality is likely to have an impact on many aspects of employee behavior within the workplace including absenteeism, error-making, and alertness at work. ${ }^{2}$ Insomnia-related absenteeism and accidents are known to
Correspondence: Saad Mohammed AlShareef

Department of Medicine, College of Medicine, Imam Mohammad Ibn Saud Islamic University (IMSIU), PO Box 7544, Riyadh 13317-4233, Saudi Arabia

Email drsaad32I@hotmail.com 
represent a significant economic burden to the individual, healthcare systems, and employers. ${ }^{3}$ Clinical studies on the occupational consequences of sleep quality have tended to focus on specific reversible conditions such as obstructive sleep apnea, since this is the commonest sleep disorder affecting the general population, ${ }^{4-6}$ although the occupational impact of sleep disorders such as insomnia have also been thoroughly investigated. ${ }^{6}$ Economically driven studies have tended to explore the impact of shift work rather than individual measures of sleep dysfunction on occupational outcomes such as absenteeism. ${ }^{6,7}$

Although there is no standardized definition, excessive daytime sleepiness (EDS) refers to the subjective or objective inclination or compulsion to sleep or nap when intending to be awake. ${ }^{8}$ While the prevalence of EDS in community-based samples varies, EDS is common, affecting anywhere between $3 \%$ and $38 \%$ of the population depending on the definition of EDS and the methodology used. ${ }^{9}$ In community-based samples, EDS is associated with high body mass index (BMI), diabetes mellitus, depression, and reduced quality of life. ${ }^{10,11}$ However, the majority of studies examining the impact of EDS on occupational parameters have focused on the relationships between EDS and specific medical conditions such as obstructive sleep apnea, ${ }^{12}$ narcolepsy, ${ }^{12}$ multiple sclerosis, ${ }^{13}$ and depression, ${ }^{8}$ The relationship between EDS and occupational productivity is rather less well characterized at the population level.

This study investigated the impact of sleep quality and EDS on occupational outcomes by gathering data via a population-wide survey of adults in Saudi Arabia. Specifically, demographic parameters, sleep quality, and EDS and their relationships with the occupational outcomes of sleep-related absenteeism, sleep-related errors made at work, and falling asleep at work were investigated. This first population-wide evaluation of sleep quality, EDS, and occupational outcomes in Saudi Arabia not only highlights the burden of sleep-related disorders within the population but also that these problems contribute to poor occupational functioning.

\section{Methods}

\section{Population and Study Survey}

This was a cross-sectional study of Saudi Arabian adults aged 18 years and over conducted between November 6, 2019, and December 6, 2019. The national survey was conducted online by a research and marketing organization, targeting a large panel database of the Saudi population randomly selected from organization panels and invited to complete the survey. Participants were randomly selected from the Saudi Telecom Company database representing all thirteen Saudi provinces and representing different age groups, gender, and location. Invitations to participate included e-mail invitations and telephone alerts. The purpose of the research was mentioned in the primary message along with the principal investigator details. Electronic consent was obtained from each participant before participation, and the IRB of Imam Mohammad Ibn Saud Islamic University approved the study protocol.

\section{Study Questionnaire}

The questionnaire (see Supplementary Information in Supplementary Materials) was designed based on the study objectives and previously published survey instruments to assess: (i) study population demographics (gender, age, height, weight, marital status, type of work (manual/office), and whether or not sleeping medications had been taken in the preceding month (never/several days $/>50 \%$ of days/nearly every day)); (ii) sleep quality including subjective assessment of sleep quality (very good, fairly good, fairly bad, very bad), sleep latency (time taken before falling asleep), sleep duration (in hours), and time going to bed or waking up on an average working day to allow the calculation of sleep efficiency (proportion of time spent asleep whilst in bed, expressed as a percentage); (iii) Epworth sleepiness scale (ESS), using a validated questionnaire consisting of eight items that assesses the likelihood of falling asleep during a variety of daily living situations (subcategorized into 0-10 normal daytime sleepiness, 11-12 mild excessive daytime sleepiness, 13-15 moderate excessive daytime sleepiness, 16-24 severe excessive daytime sleepiness; where scores $\geq 11$ were considered EDS) ${ }^{14}$ and (iv) effects of sleep on employment including sleep-related absenteeism, making errors, and falling asleep at work over the preceding three months. The questionnaire was administered in Arabic, and the validated Arabic version of the ESS was used. ${ }^{15}$

\section{Outcome Measures}

Three outcomes were investigated and assessed: (i) missing work over the past three months due to sleepiness and/ or a sleep-related problem (yes/no); (ii) making errors at work over the past three months due to sleepiness and/or 
a sleep-related problem (yes/no); and (iii) falling asleep at work over the past three months (yes/no).

\section{Statistical Analysis}

Participant demographics were analyzed using descriptive statistics with means ( \pm standard deviation (SD)) for continuous variables and counts (with percentages) for categorical variables. For univariate analysis, differences between continuous variables were assessed using Student's $t$-test and differences between categorical variables were assessed using the chi-squared test. Parameters with $\mathrm{p}$-values $<0.25$ in univariate analysis were used to design the most appropriate binary logistic regression model for each outcome variable, since lower p-value thresholds such as 0.05 can fail to identify variables known to be important. ${ }^{16,17}$ In binary logistic regression models, sleeping medications, subjective sleep quality, and sleep latency variables were binarized (sleeping medications: no use vs any use; subjective sleep quality: very good and fairly good vs fairly bad and very bad; and sleep latency: 0-29 minutes vs $>30$ minutes). For the outcomes of sleep-related absenteeism and errors at work, only demographic variables were input into binary logistic regression models since sleep quality and EDS would be expected to be related to these outcomes, whilst falling asleep at work is not directly linked to sleep problems. There were no strong intercorrelations between variables. Odds ratios were calculated with $95 \%$ confidence intervals (CIs). A p-value $<0.05$ was considered statistically significant. All analyses were performed using IMS SPSS Statistics v24 (IBM Statistics, Chicago, IL).

\section{Results}

\section{Overall Population}

A total of 10,106 individuals completed all or part of the survey, of whom $8617(85.3 \%)$ provided details of their employment: $5648(65.5 \%)$ of employed workers were employed in office jobs ("white-collar workers"), 626 $(7.3 \%)$ were manual workers ("blue-collar" workers), while $2343(27.2 \%)$ described themselves as unemployed.

The demographics of the employed survey respondents are shown in Table 1. Of employed respondents, 55.3\% were male and $44.7 \%$ were female. The average age of employed respondents was $30.5(\mathrm{SD} \pm 10.4)$ years, with an average BMI of $27.4(\mathrm{SD} \pm 7.8) \mathrm{kg} / \mathrm{m}^{2}$. Of employed respondents, $52.5 \%$ were single, $44.3 \%$ were married, $2.9 \%$ were divorced, and $0.2 \%$ were widowed. About
Table I Demographics of the Employed Survey Respondents

\begin{tabular}{|c|c|c|c|}
\hline Variables & & Number & $\begin{array}{l}\text { Percentage or } \\
\text { Mean } \pm \text { SD }\end{array}$ \\
\hline Age (years) & & 6274 & $30.5(10.4)$ \\
\hline \multirow[t]{2}{*}{ Gender } & Male & 3489 & 55.3 \\
\hline & Female & 2817 & 44.7 \\
\hline BMI $\left(\mathrm{kg} / \mathrm{m}^{2}\right)$ & & 6264 & $27.4(7.8)$ \\
\hline \multirow[t]{4}{*}{ Marital status } & Married & 2779 & 44.3 \\
\hline & Divorced & 185 & 2.9 \\
\hline & Single & 3295 & 52.5 \\
\hline & Widowed & 15 & 0.2 \\
\hline \multirow{2}{*}{$\begin{array}{l}\text { Type of } \\
\text { employment }\end{array}$} & Manual & 626 & 10.0 \\
\hline & Office & 5648 & 90.0 \\
\hline \multirow{4}{*}{$\begin{array}{l}\text { Sleeping } \\
\text { medications }\end{array}$} & Never & 5544 & 85.1 \\
\hline & Several days & 706 & 10.8 \\
\hline & $\begin{array}{l}\text { More than half } \\
\text { of days }\end{array}$ & 152 & 2.3 \\
\hline & $\begin{array}{l}\text { Nearly } \\
\text { every day }\end{array}$ & 114 & 1.7 \\
\hline
\end{tabular}

$15 \%$ of respondents had taken some form of medication to aid sleep in the preceding month, the majority of whom $(10.8 \%)$ had taken medication only infrequently.

\section{Prevalence of Sleep Quality Parameters and Daytime Sleepiness}

With respect to sleep quality and daytime sleepiness (Table 2), according to self-reported quality of sleep, the prevalence of poor sleep quality was high in employed respondents, with $28.7 \%$ and $8.8 \%$ reporting "fairly bad" or "very bad" sleep quality in the preceding month. Of employed respondents, $35.4 \%$ reported taking over 30 minutes to fall asleep. The average sleep duration was 6.49 hours $(\mathrm{SD} \pm 2.03)$ and average sleep efficiency was $85.1 \%$ (SD $\pm 30.4 \%$ ). A majority (63.2\%) of employed respondents reported at least mild excessive daytime sleepiness (ESS $\geq 11$ ), with 9.4\% and 5.3\% reporting moderate EDS (ESS 13-15) and severe EDS (ESS $\geq 16$ ), respectively.

\section{Associations Between Demographic and Sleep Parameters and Occupational Outcomes}

Almost all demographic and sleep variables were associated with missing work, making errors at work, or falling 
Table 2 Prevalence of Sleep-Related Parameters in the Employed Survey Respondents

\begin{tabular}{|l|l|l|l|}
\hline Variables & & Number & $\begin{array}{l}\text { Percentage } \\
\text { or Mean } \text { 士SD }\end{array}$ \\
\hline Subjective sleep quality & Very good & 1216 & 15.7 \\
& Fairly good & 3638 & 46.9 \\
& Fairly bad & 2228 & 28.7 \\
& Very bad & 681 & 8.8 \\
\hline Sleep latency & $0-5$ minutes & 569 & 7.3 \\
& $5-15$ minutes & 2114 & 27.2 \\
& $15-30$ minutes & 2334 & 30.1 \\
& $>30$ minutes & 2746 & 35.4 \\
\hline Sleep duration (h) & & 7763 & $6.49(2.03)$ \\
\hline Sleep efficiency (\%) & & 7671 & $85.1(30.4)$ \\
\hline Epworth Sleepiness Scale & Normal & 2805 & 36.1 \\
& Low & 3813 & 49.1 \\
& Moderate & 730 & 9.4 \\
& Severe & 415 & 5.3 \\
\hline
\end{tabular}

asleep at work in the preceding three months in univariate analysis (Supplementary Table S1). Absenteeism, errors, and falling asleep at work were associated with being female, younger, having a lower BMI, being single, and taking sleeping medications.

With respect to sleep quality parameters, individuals reporting very/fairly bad sleep quality or more severe EDS were more likely to fall asleep at work; sleep efficiency, longer sleep duration, and longer sleep latency were not associated with falling asleep at work. In particular, $84.4 \%$ of individuals with severe EDS had fallen asleep at work in the preceding three months.

Binary logistic regression models were constructed to examine which demographic (sleep-related absenteeism, sleep-related errors, and falling asleep at work) or sleep parameters (falling asleep at work) were associated with occupational outcomes in the entire working population (Figure 1 and Supplementary Table S2) and in blue- and white-collar workers (Figure 2 and Supplementary Table S2). Older individuals were more likely to be absent, make errors, or fall asleep at work due to sleep-related problems (all ORs 0.95-0.96; $\mathrm{p}<0.001)$. Male, divorced, white-collar workers were more likely to be absent but not make errors or fall asleep at work. Taking sleeping medications was associated with a $\sim 1.9$-fold risk of missing work and making errors at work but not falling asleep at work.

With respect to sleep-related parameters, individuals reporting fairly or very bad sleep quality were consistently more likely to fall asleep at work (OR 1.55, 95\% CI 1.38-1.74; $\mathrm{p}<0.001)$. Excessive daytime sleepiness was also associated with falling asleep at work, with individuals with severe EDS having a 3.39-fold (95\% CI $2.51-4.58 ; \mathrm{p}<0.001)$ risk compared to individuals without EDS.

There was little difference in occupational outcomes between blue- and white-collar workers (Figure 2 and Supplementary Table S2). Younger age and taking sleeping medications were associated with absenteeism and making errors at work but not falling asleep at work in both blue- and white-collar workers. In addition, blue- and white-collar workers reporting very or fairly bad sleep quality and moderate and severe EDS were more likely to fall asleep at work.

\section{Discussion}

This study provides new data on the prevalence of sleep quality and EDS in a large representative sample of the adult Saudi Arabian population and their impact on
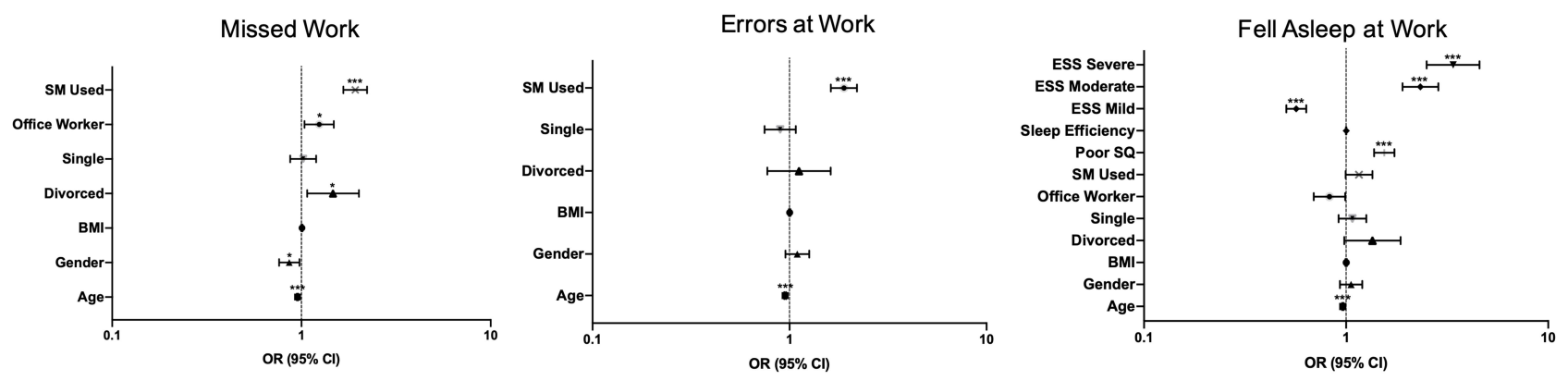

Figure I Binary logistic regression examining the associations between demographic and sleep parameters and missing work, making errors at work, or falling asleep at work for the entire employed population. Reference categories are male for gender, married for marital status, manual worker for employment type, never took sleeping medications for sleeping medications, good sleep quality for subjective sleep quality, 0-29 minutes for sleep latency, and normal for ESS. Points represent odds ratios (OR), error bars represent $95 \%$ confidence intervals $(\mathrm{Cl}) .{ }^{*} \mathrm{p}<0.05$; $* * * \mathrm{p}<0.001$.

Abbreviations: BMI, body mass index; SM, sleep medication; SQ, sleep quality; SL, sleep latency; ESS, Epworth Sleepiness Scale. 

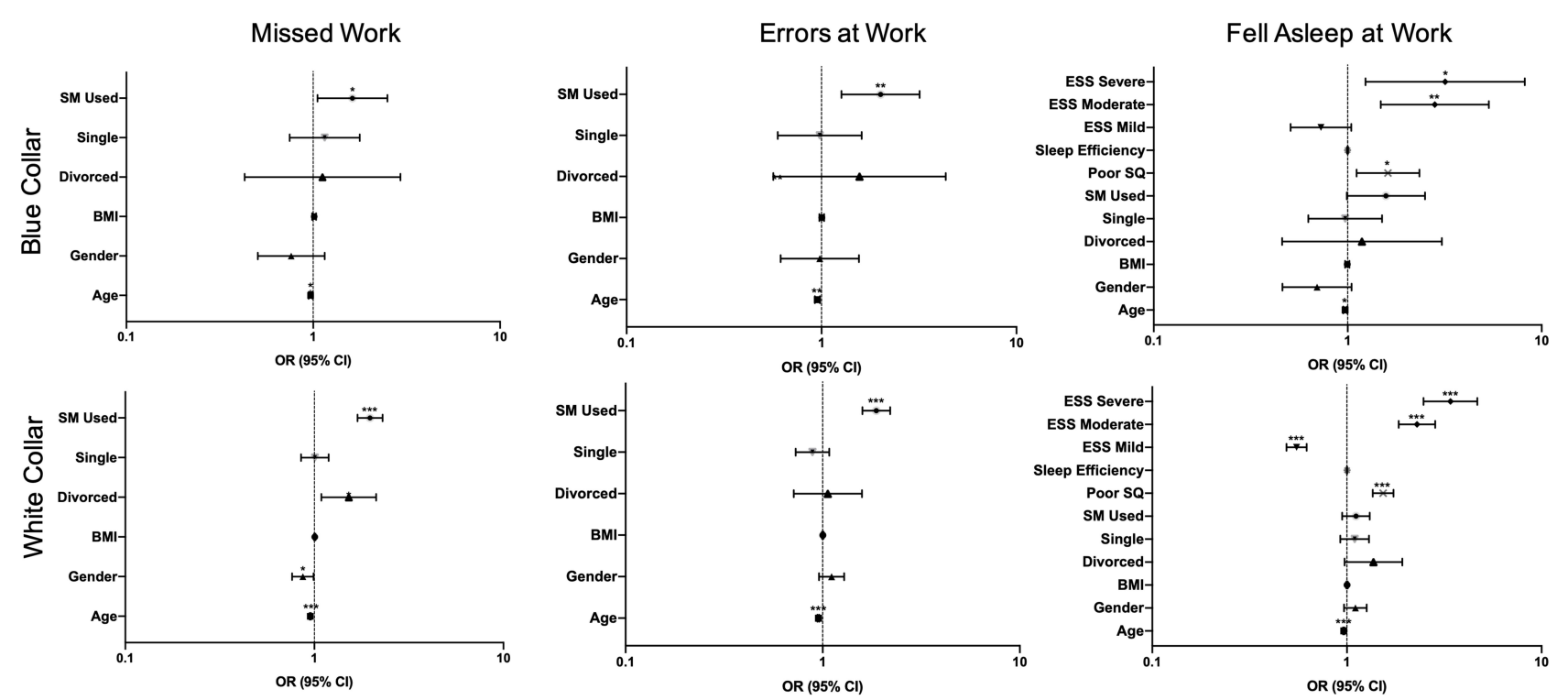

Figure 2 Binary logistic regression examining the associations between demographic and sleep parameters and missing work, making errors at work, or falling asleep at work for blue- and white-collar workers. Reference categories are male for gender, married for marital status, manual worker for employment type, never took sleeping medications for sleeping medications, good sleep quality for subjective sleep quality, 0-29 minutes for sleep latency, and normal for ESS. Points represent odds ratios (OR), error bars represent $95 \%$ confidence intervals $(\mathrm{Cl})$. ${ }^{*} \mathrm{p}<0.05$; **p $<0.01$; ***p $<0.001$.

Abbreviations: BMI, body mass index; SM, sleep medication; SQ, sleep quality; SL, sleep latency; ESS, Epworth Sleepiness Scale.

occupational outcomes. Similar to other populations and ethnicities, Saudi Arabia experiences a high burden of sleep dysfunction: $37.5 \%$ of respondents self-reported fairly or very bad sleep quality; $35.4 \%$ took over half an hour to fall asleep; and $14.7 \%$ had moderate or severe EDS. Although the relationships between demographics, sleep and daytime sleepiness parameters, and sleep-related occupational outcomes were complex, sleep-related parameters remained associated with falling asleep at work in multivariate analyses. In particular, taking sleep medications was associated with absenteeism and making errors at work and the subjective appreciation of poor-quality sleep was strongly associated with falling asleep at work. EDS was consistently and proportionately associated with falling asleep at work, conferring up to a 3.4-fold risk of falling asleep at work in individuals with severe EDS (ESS 216). These effects were largely the same in blue- and white-collar workers.

Occupational dysfunction is recognized as a consequence of insomnia in the Diagnostic and Statistical Manual of Mental Disorders, 4th edition (DSM-IV $(\mathrm{TR}))^{18}$ and the International Classification of Sleep Disorders Diagnostic and Coding Manual (ICSD-3). ${ }^{12}$ In a review reporting associations between various insomnia symptoms and definitions and their impact on a range of job types, most studies reported significantly increased absenteeism in individuals reporting insomnia symptoms. ${ }^{6}$ For instance, in a Swedish study of over two thousand working-age adults, $7 \%$ and $13 \%$ of individuals reporting subjective "good" and "poor" sleep reported being off work in the previous week, respectively. ${ }^{19}$ Although not directly comparable in terms of the definitions used, $33.2 \%$ and $50.3 \%$ of the current sample were absent due to sleep-related problems at some point over the previous three months in individuals reporting very good sleep quality vs those reporting very bad sleep quality, respectively. Similarly, in a cross-sectional survey of 5090 white-collar workers in Japan, ${ }^{20}$ the one-month point prevalence of poor sleep quality defined using the Pittsburgh Sleep Quality Index (PSQI) was 30-45\% depending on age and gender, similar to the $37.5 \%$ of participants reporting fairly or very bad sleep quality here, and $16.5 \%$ were absent from work in the preceding month. Demographic parameters such as age and gender were significantly associated with absenteeism, which is a well-known association; ${ }^{21,22}$ women, for example, have much higher rates of sickness absence unrelated to the menstrual cycle or pregnancies, ${ }^{21}$ and our data show that sleep-related absenteeism might also contribute to this gender difference.

There are little data on the influence of sleep quality on occupational parameters in the general working 
population, with most studies concentrating on particular workers such as nurses ${ }^{23}$ or shift-related work. ${ }^{24}$ In a study of 1011 Australian adults completing the 2016 Sleep Health Foundation Survey, ${ }^{25}$ 29\% of respondents reported making errors at work due to sleepiness or sleep problems over the preceding month, similar to the $24 \%$ over the previous three months reported here. Only $\sim 17 \%$ of the Australian sample had fallen asleep at work over the previous month, which compares to $\sim 54 \%$ in the current sample. The current study discovers some factors that might influence making errors and falling asleep at work. In particular, taking sleeping medications was associated with making errors at work (OR 1.89, 95\% CI 1.62-2.20; $\mathrm{p}<0.001$ ) but not falling asleep at work (OR 1.16, 95\% CI $1.00-1.35 ; \mathrm{p}=0.06$ ) compared to those not taking any sleep medications, and severe EDS was strongly associated with falling asleep at work (OR 3.39, 95\% CI 2.51-4.58; $\mathrm{p}<0.001)$ compared to individuals without EDS. A followon study from the 2016 Sleep Health Foundation Survey similarly examined factors related to errors at work, with younger age, financial stress, mental health problems, regular night or afternoon shifts, and work in the hour before bed on three or more nights per week all significantly associated in multivariate analysis. ${ }^{26}$ The current analysis similarly found that younger age was associated with an increased risk of sleep-related work errors. However, while the Sleep Health Foundation Survey did not examine sleeping medication use, the finding of an increased risk of errors in frequent sleeping medication users is consistent with factors beyond clinical sleep disorders influencing errors at work and, given the psychotropic effects of some sleeping tablets, this association may be causal. However, it is also worth noting that sleeping tablet consumption has been reported to be higher in individuals reporting a bad atmosphere at work, men disinterested in their jobs, or women working under time pressure, all of whom were more likely to report sleep disturbances. ${ }^{27}$ It would have been useful to establish which specific sleeping tablets were taken, since the residual (ie, daytime) effects of different hypnotics (ie, antihistamines vs benzodiazepines) are radically different. ${ }^{28}$ Therefore, a more granular study of the relationship between sleeping tablet consumption, different types of sleeping tablets, and occupational performance, including errors, is warranted.

EDS, as measured by the Epworth Sleepiness Scale, was significantly associated with a greater risk of falling asleep at work (OR 3.39, 95\% CI 2.51-4.48; p<0.001). Furthermore, this effect of EDS on falling asleep at work was proportional to severity, with severe EDS (ESS $\geq 16$ ) conferring the greatest risk. It is perhaps unsurprising that EDS is associated with falling asleep at work, which provides some internal validation of our approach. This study only examined absenteeism and work errors due to sleepiness or sleep-related problems. However, in other population-based samples examining sickness absenteeism and making general errors at work, Ferguson et al reported a three-times greater risk of errors at work in the previous three months with ESS scores $\geq 11,{ }^{26}$ while Reynolds et al reported a 1.4-times risk of sickness absenteeism in their sample of participants without diagnosed insomnia or obstructive sleep apnea (OSA). ${ }^{29}$ Conversely, Dean et al did not detect any differences in a group of nearly two thousand individuals without conditions in which EDS is a common feature (OSA, narcolepsy, depression, and MS) but did within the co-morbid-enriched subgroup, ${ }^{30}$ suggesting that co-morbid factors other than EDS might have a greater influence on absenteeism.

There are little data on the relationships between sleep quality and EDS and occupational outcomes between blueand white-collar workers, with the majority of studies focusing on shift-workers alone. Doi et al reported the impact and correlates of poor sleep quality in a population of Japanese white-collar employees ${ }^{20}$ and found that poor sleep quality as assessed by the Pittsburgh Sleep Quality Inventory (PSQI) was associated with a higher odds of taking sick leave and accidents at work, mirroring other data in general populations. Mulgrew et al examined the impact of sleep apnea and daytime sleepiness on work limitations and examined the differences between blue- and white-collar workers, establishing that subjective sleepiness was significantly associated with time management, mental-inter-personal, and work output limitations for all workers regardless of their industry of employment. ${ }^{31}$ The current analysis suggests that the relationships between sleep, employment type, and occupational outcomes are largely similar in blue- and white-collar workers. Nevertheless, identifying the underlying causes of errors at work in blue-collar workers employed in manual jobs such as on building sites is particularly important, since these errors might result in life-threatening injury, and here taking sleeping medications was associated with blue-collar errors at work (OR 2.01). Strategies aiming to reduce adverse sleep-related outcomes in the workplace must be tailored towards the specific occupational environment. 
Our study has a number of limitations. This was a selfreporting survey, and many people tend to overestimate sleep latency and underestimate total time asleep. ${ }^{32}$ Nevertheless, self-reported poor sleep quality is associated with morbidity and mortality outcomes, ${ }^{33-36}$ suggesting that, despite the possibility of self-reporting error, this is a valid parameter consistently associated with health outcomes. However, this might also mean that any underlying health conditions not assessed in the current study might attenuate the reported findings. The available survey sample was from those enrolled in the online panel, and this may have introduced selection bias. In addition, since the purpose of the research was disclosed to prospective participants, this might have resulted in responder bias. Nevertheless, the male: female ratio (1.2:1 vs $1.3: 1)$, young median age of the sample (29 years vs 29.9 years), and high obesity prevalence ( $32 \%$ vs $35.4 \%$ ) are highly consistent with key sociodemographic statistics for Saudi Arabia, ${ }^{37}$ increasing confidence that the survey is representative of the wider population. Similar to the Sleep Health Foundation Survey, ${ }^{26}$ a definition of "error at work" was not provided, so respondents self-determined what constituted an error at work, and not all errors at work will be directly related to sleepiness or sleep issues even if self-identified as such. Other confounders that might affect sleepiness such as caffeine intake, shift work, and comorbidities were not included in the analysis and might reduce or abrogate these effects in progressively adjusted outcome models. ${ }^{38,39}$ As with all cross-sectional studies, causality cannot be inferred.

Nevertheless, this is the first population-wide study of sleep quality and EDS in Saudi Arabia and is one of the largest cross-sectional population-based studies of its kind. It therefore provides a comprehensive portrait of the prevalence of sleep problems and their effects on occupational outcomes in Saudi Arabia. Like in other countries, there is a high burden of sleep-related dysfunction in Saudi Arabia, which given its impact on health, waking function, and short- and long-term wellbeing, constitutes a public health priority. Sleep-related absenteeism, work errors, and sleeping at work are common and reported by all workers, mandating fatigue-reduction strategies in every workplace. There is clearly a need for reinvigorated public health messages on sleep and, given that our population readily self-identified sleep-related occupational problems, awareness and engagement initiatives are likely to be effective at the population level.

\section{Ethical Approval}

The project was approved by the internal review board (IRB) of Imam Mohammad Ibn Saud Islamic University (IMSIU).

\section{Consent to Participate}

Electronic consent was obtained from each participant before participation.

\section{Author Contributions}

The author conceived, designed, executed, acquired, analysed and interpreted the data; drafted, revised, and critically reviewed the article; gave final approval of the version to be published; agreed on the journal to which the article has been submitted; and agrees to be accountable for all aspects of the work.

\section{Disclosure}

The author reports no conflicts of interest for this work.

\section{References}

1. Chanchlani N. Health consequences of shift work and insufficient sleep. BMJ. 2017;356:i6599. doi:10.1136/sbmj.i6599

2. Pilcher JJ, Morris DM. Sleep and organizational behavior: implications for workplace productivity and safety. Front Psychol. 2020;11:45. doi:10.3389/fpsyg.2020.00045

3. Metlaine A, Leger D, Choudat D. Socioeconomic impact of insomnia in working populations. Ind Health. 2005;43(1):11-19. doi:10.2486/ indhealth.43.11

4. Ulfberg J, Carter N, Talback M, Edling C. Excessive daytime sleepiness at work and subjective work performance in the general population and among heavy snorers and patients with obstructive sleep apnea. Chest. 1996;110(3):659-663. doi:10.1378/chest.110.3.659

5. Jurado-Gamez B, Guglielmi O, Gude F, Buela-Casal G. Workplace accidents, absenteeism and productivity in patients with sleep apnea. Arch Bronconeumol. 2015;51(5):213-218. doi:10.1016/j.arbres.2014. 07.003

6. Kucharczyk ER, Morgan K, Hall AP. The occupational impact of sleep quality and insomnia symptoms. Sleep Med Rev. 2012;16 (6):547-559. doi:10.1016/j.smrv.2012.01.005

7. Yazdi Z, Sadeghniiat-Haghighi K, Loukzadeh Z, Elmizadeh K, Abbasi M. Prevalence of sleep disorders and their impacts on occupational performance: a comparison between shift workers and nonshift workers. Sleep Disord. 2014;2014:870320. doi:10.1155/2014/ 870320

8. Young TB. Epidemiology of daytime sleepiness: definitions, symptomatology, and prevalence. J Clin Psychiatry. 2004;65(Suppl 16):12-16.

9. Kolla BP, He JP, Mansukhani MP, Frye MA, Merikangas K. Excessive sleepiness and associated symptoms in the U.S. adult population: prevalence, correlates, and comorbidity. Sleep Health. 2020;6(1):79-87. doi:10.1016/j.sleh.2019.09.004

10. Fernandez-Mendoza J, Vgontzas AN, Kritikou I, Calhoun SL, Liao D, Bixler EO. Natural history of excessive daytime sleepiness: role of obesity, weight loss, depression, and sleep propensity. Sleep. 2015;38(3):351-360. doi:10.5665/sleep.4488 
11. Hasler G, Buysse DJ, Gamma A, et al. Excessive daytime sleepiness in young adults: a 20-year prospective community study. J Clin Psychiatry. 2005;66(4):521-529. doi:10.4088/jcp.v66n0416

12. Medicine AAoS. International classification of sleep disorders. Diagnostic Coding Manual. 2005;51-55.

13. Stanton BR, Barnes F, Silber E. Sleep and fatigue in multiple sclerosis. Mult Scler. 2006;12(4):481-486. doi:10.1191/135248506ms1320oa

14. Johns MW. A new method for measuring daytime sleepiness: the Epworth sleepiness scale. Sleep. 1991;14(6):540-545.

15. Ahmed AE, Fatani A, Al-Harbi A, et al. Validation of the Arabic version of the Epworth sleepiness scale. J Epidemiol Glob Health. 2014;4(4):297-302. doi:10.1016/j.jegh.2014.04.004

16. Bendel RB, Afifi AA. Comparison of stopping rules in forward "stepwise" regression. J Am Stat Assoc. 1977;72(357):46-53.

17. Mickey RM, Greenland S. The impact of confounder selection criteria on effect estimation. Am J Epidemiol. 1989;129(1):125-137. doi:10.1093/oxfordjournals.aje.a115101

18. Edition F. Diagnostic and statistical manual of mental disorders. Am Psychiatric Assoc. 2013.

19. Linton SJ, Bryngelsson L. Insomnia and its relationship to work and health in a working-age population. J Occup Rehabil. 2000;10 (2):169-183.

20. Doi Y, Minowa M, Tango T. Impact and correlates of poor sleep quality in Japanese white-collar employees. Sleep. 2003;26 (4):467-471. doi:10.1093/sleep/26.4.467

21. Markussen S, Roed K, Rogeberg OJ, Gaure S. The anatomy of absenteeism. J Health Econ. 2011;30(2):277-292. doi:10.1016/j. jhealeco.2010.12.003

22. Firat H, Yuceege M, Kiran S, et al. Absenteeism and delay to work due to sleep disorders in the Turkish adult population: a questionnaire-based national survey. Workplace Health Saf. 2019;67 (1):27-35. doi:10.1177/2165079918785392

23. Caruso CC, Hitchcock EM. Strategies for nurses to prevent sleep-related injuries and errors. Rehabil Nurs. 2010;35(5):192-197. doi:10.1002/j.2048-7940.2010.tb00047.x

24. Akerstedt T. Shift work and disturbed sleep/wakefulness. Occup Med (Lond). 2003;53(2):89-94. doi:10.1093/occmed/kqg046

25. Adams RJ, Appleton SL, Taylor AW, et al. Sleep health of Australian adults in 2016: results of the 2016 sleep health foundation national survey. Sleep Health. 2017;3(1):35-42. doi:10.1016/j.sleh.2016.11.005

26. Ferguson SA, Appleton SL, Reynolds AC, et al. Making errors at work due to sleepiness or sleep problems is not confined to non-standard work hours: results of the 2016 sleep health foundation national survey. Chronobiol Int. 2019;36(6):758-769. doi:10.1080/ 07420528.2019.1578969

27. Jacquinet-Salord MC, Lang T, Fouriaud C, Nicoulet I, Bingham A. Sleeping tablet consumption, self reported quality of sleep, and working conditions. Group of occupational physicians of APSAT. J Epidemiol Community Health. 1993;47(1):64-68. doi:10.1136/jech.47.1.64
28. Vermeeren A. Residual effects of hypnotics: epidemiology and clinical implications. CNS Drugs. 2004;18(5):297-328. doi:10.2165/ 00023210-200418050-00003

29. Reynolds AC, Appleton SL, Gill TK, et al. Sickness absenteeism is associated with sleep problems independent of sleep disorders: results of the 2016 sleep health foundation national survey. Sleep Health. 2017;3(5):357-361. doi:10.1016/j.sleh.2017.06.003

30. Dean B, Aguilar D, Shapiro C, et al. Impaired health status, daily functioning, and work productivity in adults with excessive sleepiness. J Occup Environ Med. 2010;52(2):144-149. doi:10.1097/JOM.0b013e3181c99505

31. Mulgrew AT, Ryan CF, Fleetham JA, et al. The impact of obstructive sleep apnea and daytime sleepiness on work limitation. Sleep Med. 2007;9(1):42-53. doi:10.1016/j.sleep.2007.01.009

32. Harvey AG, Tang NK. (Mis)perception of sleep in insomnia: a puzzle and a resolution. Psychol Bull. 2012;138(1):77-101. doi:10.1037/ a0025730

33. Kurina LM, McClintock MK, Chen JH, Waite LJ, Thisted RA, Lauderdale DS. Sleep duration and all-cause mortality: a critical review of measurement and associations. Ann Epidemiol. 2013;23 (6):361-370. doi:10.1016/j.annepidem.2013.03.015

34. Cappuccio FP, Cooper D, D’Elia L, Strazzullo P, Miller MA. Sleep duration predicts cardiovascular outcomes: a systematic review and meta-analysis of prospective studies. Eur Heart J. 2011;32 (12):1484-1492. doi:10.1093/eurheartj/ehr007

35. Cappuccio FP, D'Elia L, Strazzullo P, Miller MA. Quantity and quality of sleep and incidence of type 2 diabetes: a systematic review and meta-analysis. Diabetes Care. 2010;33(2):414-420. doi:10.2337/ dc09-1124

36. Gangwisch JE, Heymsfield SB, Boden-Albala B, et al. Short sleep duration as a risk factor for hypertension: analyses of the first national health and nutrition examination survey. Hypertension. 2006;47(5):833-839. doi:10.1161/01.HYP.0000217362.34748.e0

37. Mundi I. Saudi Arabia demographics profile 2018. Mundi Index; 2019. Available from: http://www. indexmundi. com/saudi_arabia.

38. Kuppermann M, Lubeck DP, Mazonson PD, et al. Sleep problems and their correlates in a working population. J Gen Intern Med. 1995;10(1):25-32. doi:10.1007/BF02599573

39. Philip P, Leger D, Taillard J, et al. Insomniac complaints interfere with quality of life but not with absenteeism: respective role of depressive and organic comorbidity. Sleep Med. 2006;7(7):585-591. doi:10.1016/j.sleep.2006.04.006
Nature and Science of Sleep

\section{Publish your work in this journal}

Nature and Science of Sleep is an international, peer-reviewed, open access journal covering all aspects of sleep science and sleep medicine, including the neurophysiology and functions of sleep, the genetics of sleep, sleep and society, biological rhythms, dreaming, sleep disorders and therapy, and strategies to optimize healthy sleep.
The manuscript management system is completely online and includes a very quick and fair peer-review system, which is all easy to use. Visit http://www.dovepress.com/testimonials.php to read real quotes from published authors. 